Н. В. Шевченко, С. М. Кузнецов, А. Д. Дармаев и др. Сложный диагностический случай менингоэнцефалита у пациента с ВИЧ-инфекцией

УДК 616.831.9-002:616.9

DOI: $10.18101 / 2306-1995-2020-1-21-33$

\title{
СЛОЖНЫЙ ДИАГНОСТИЧЕСКИЙ СЛУЧАЙ МЕНИНГОЭНЦЕФАЛИТА У ПАЦИЕНТА С ВИЧ-ИНФЕКЦИЕЙ
}

\section{(C) Шевченко Николай Васильевич}

организатор здравоохранения,

подполковник медицинской службы, начальник

s.m.kusnetzov@yandex.ru

\section{(C) Кузнецов Сергей Миронович}

кандидат медицинский наук, врач хирург высшей категории, заведующий операционным отделением

s.m.kusnetzov@yandex.ru

\section{(C) Дармаев Андрей Дашиевич}

врач невролог высшей категории

darmaevad@mail.ru

\section{(C) Очиров Баир Владимирович}

подполковник медицинской службы, начальник инфекционного отделения darmaevad@mail.ru

\section{(C) Щелкова Ирина Анатольевна}

ординатор инфекционного отделения

905irina@mail.ru

\section{(C) Зырянов Андрей Анатольевич}

ординатор отделения АиР, врач анестезиолог высшей категории s.m.kusnetzov@yandex.ru

ФГКУ «425 ВГ» Минобороны России филиал № 1

Россия, 664009, г. Иркутск, ул. Госпитальная, 1 


\section{(C) Пыренков Денис Александрович}

подполковник медицинской службы, врач анестезиолог, начальник отделения АиР Астраханский гарнизонный госпиталь Россия, 414000, г. Астрахань, ул. Розы Люксембург, 5 s.m.kusnetzov@yandex.ru

\section{(C) Мицкевич Антон Сергеевич} капитан медицинской службы, начальник отделения анестезиологии и реанимации (АиР) mits.oar38mail.ru

\section{(C) Ващенко Павел Павлович}

капитан медицинской службы, ординатор отделения АиР darmaevad@mail.ru

\section{(C) Шинкоренко Виктория Станиславовна} врач невролог высшей категории, заведующая неврологическим отделением поликлинического звена, vikstan24@mail.ru

ФГКУ «425 ВГ» Минобороны России филиал № 1 Россия, 664009, г. Иркутск, ул. Госпитальная, 1

\section{(C) Макарова Наталья Александровна} врач-невролог отделения первичной специализированной медико-санитарной помощи ОГБУЗ «ИГКБ № 3» Россия, 664003, г. Иркутск, Тимирязева, 31 mak.na@list.ru

\section{(C) Таргашина Татьяна Борисовна} подполковник медицинской службы, начальник терапевтического отделения targashina.t@mail.ru 
Н. В. Шевченко, С. М. Кузнецов, А. Д. Дармаев и др. Сложный диагностический случай менингоэнцефалита у пациента с ВИЧ-инфекцией

\title{
(C) Сидельников Алексей Петрович
}

врач невролог высшей категории

1007Petr@mail.ru

\section{(C) Онищук Юлия Владимировна}

врач терапевт, начальник приемного отделения

onishchuk.y@inhox.ru

\author{
ФГКУ «425 ВГ» Минобороны России \\ филиал № 1 \\ Россия, 664009, г. Иркутск, ул. Госпитальная, 1
}

\begin{abstract}
Аннотация. В статье приводится клиническое наблюдение пациента с трудно верифицируемым менингоэнцефалитом на фоне ВИЧ-инфекции. При поступлении в стационар у пациента не выявлено ни одного типичного симптома для менингоэнцефалита, отмечено наличие выраженных отеков на ногах, госпитализирован в терапевтическое отделение. Состояние пациента ухудшалось, переведен в ОРиИТ. Только динамическое наблюдение, привлечение для консультаций специалистов всех профилей, использование овременных компьютерных технологий позволило диагностировать вирусный менингоэнцефалит.
\end{abstract}

Ключевые слова: менингоэнцефалит; ВИЧ-инфекция.

\section{Для цитирования}

Сложный диагностический случай менингоэнцефалита у пациента с ВИЧ-инфекцией / Н. В. Шевченко [и др.] // Вестник Бурятского государственного университета. Медицина и формация 2020. Вып. 1. C. 21-33.

МЕНИНГОЭНЦЕФАЛИТ - воспаление оболочек и вещества головного и спинного мозга, обычно инфекционного генеза. Менингоэнцефалиты классифицируют по этиологии (бактериальный, вирусный, грибковый и т. д.), характеру воспалительного процесса (гнойный, серозный), течению (острый, подострый, хронические), происхождению (первичный и вторичный, возникающий на фоне другого заболевания: отита, синусита, ЧМТ и т. д.).

Клиническую картину менингита составляют общеинфекционные симптомы (лихорадка, недомогание, тахикардия, миалгии), общемозговые симптомы (интенсивная головная боль, тошнота, рвота, спутанность или угнетение сознания вплоть до комы) и очаговые симптомы (анизорефлексия, парезы, параличи). 
Менингеальный синдром включает ригидность шейных мышц, симптом Кернига, симптомы Брудзинского, общую гипертензию, реактивные болевые феномены.

Менингеальный симптомы часто можно выявить даже в коме, однако на ранней стадии заболевания, а также у детей и пожилых они могут отсутствовать. У пожилых людей менингоэнцефалит может проявиться сочетанием лихорадки со спутанностью или нарастающим угнетением сознания в отсутствие менингеальных и очаговых симптомов. С другой стороны, ригидность шейных мышц у пожилых может быть следствием шейного остеохондроза, паркинсонизма, паратонии. В отличие от этих состояний при менингите затруднено лишь сгибание шеи, но не ее ротация или разгибание. У больных с ослабленным иммунитетом менингоэнцефалит протекает как легкая инфекция с умеренной лихорадкой и головной болью либо как быстро нарастающая кома, при отсутствии очаговых симптомах. Помимо менингита, менингеальные симптомы («менингизм») могут выявляться при субарахноидальном кровоизлиянии, внутричерепной гипертензии, объемных процессах в задней черепной ямке (гематоме или абсцессе мозжечка), интоксикации, ЧМТ, злокачественном нейролептическом синдроме.

Решающее значение в диагностике менингита имеет исследование ЦСЖ. В связи с этим ЛП обязательна при малейшем подозрении на менингит, однако она может быть опасна в связи с возможностью вклинения. В связи с этим перед ЛП нужно определить, нет ли признаков резкого повышения ВЧД или объемного процесса (неуклонно нарастающей очаговой или общемозговой симптоматики, фокальных припадков и особенно признаков поражения задней черепной ямки - дисфункции черепных нервов, мозжечковой атаксии), исследовать глазное дно (для выявления застойных дисков зрительных нервов) или провести ЭхоЭС (исключить смещение срединных структур). Более надежно исключает объемный процесс КТ, МРТ, МСКТ головного мозга.

Лечение больных менингоэнцефалитом с сочетанием с ВИЧинфекции представляет серьезные трудности, из-за пониженного иммунитета у таких больных, резистентности проводимой терапии.

Стремительное развитие медицинской и фармацевтической науки, внедрение современных методов диагностики, создание новых антибактериальных препаратов не позволили до конца решить проблему гнойновоспалительных осложнений (ГВО) у таких больных. Увеличивается число тяжело протекающих и не поддающихся традиционному лечению осложненных форм гнойных внутричерепных процессов. Несмотря на использование в клинической практике новых антибиотиков, прогноз для больных с внутричерепными ГВО остается неблагоприятным. Суммарная 
летальность при ГВО составляет 5-15\%, достигая при бактериальных менингоэнцефалитах (МЭ) $25 \%$, вентрикулитах - $80 \%$, абсцессах головного мозга - 21-60\%. Одной из причин высокой летальности является увеличение числа антибиотикорезистентной микрофлоры.

Инфекционные поражения вещества головного мозга, мозговых оболочек и ликворосодержащих пространств, в силу особого положения центральной нервной системы в организме, представляют собой чрезвычайно грозные состояния, требующие принятия энергичных мер уже при появление первых признаков неблагополучия, ухудшении неврологического статуса. При лечении гнойных процессах ведущим методом терапии является этиотропный. Однако лечение внутричерепных бактериальных инфекций центральной нервной системы имеет свои особенности, обусловленные несовершенством местных защитных сил организма по отношению к инфекции и физиологией гематоэнцефалического барьера (ГЭБ), затрудняющего, в частности, проникновение лекарственных средств в патологический очаг.

Эффективность терапии определяется, прежде всего, правильным подбором антибактериального препарата. Для этого необходимо знание его антимикробного спектра действия, чувствительности к нему возбудителя, особенностей фармакокинетики и фармакодинамики. Существенное значение для повышения эффективности лечения имеет выбор метода введения антибиотика и особенности его сочетания с другими препаратами (синергизм, аддитивность, антагонизм). В итоге, успех антибиотикотерапии определяется возможностью препарата создавать терапевтическую концентрацию в области пораженных тканей для конкретного возбудителя.

При лечении МЭ следует учитывать способность антибиотика проникать через ГЭБ. Принято считать, что для полной стерилизации ликвора концентрация антибиотика должна в десять и более раз превышать видовую минимальную бактерицидную концентрацию возбудителя.

На способность антибиотиков при их парентеральном применении проникать в ликвор оказывать влияние ряд факторов: состояние ГЭБ, растворимость препаратов в липидах, степень их связывания белками сыворотки крови. Многие антибиотики практически не попадают в ликвор при наличии неизменного барьера. При гнойных послеоперационных осложнений у нейрохирургических больных, как правило, ГЭБ нарушен изначально, однако наличие локального повреждения барьера в зоне оперативного вмешательства не снижает его роли на других участках мозга в регулировании проникновения антибиотиков в цереброспинальную жидкость (ЦСЖ). В условиях развивающегося воспаления оболочек мозга проницаемость барьера увеличивается в 3-6 раз, что дает возможность достижения бактерицидных концентраций в ЦСЖ. 
При гнойных МЭ основным путем введения антибактериальных препаратов является внутривенный. Наличие ГЭБ не всегда позволяет достичь бактерицидной концентрации в тканях мозга и ЦСЖ, что ограничивает использование антибиотиков данным путем введения. Одним из наиболее эффективных вариантов решения этой проблемы является использование интратекального пути введения антибактериальных препаратов, который позволяет создать оптимальную бактерицидную концентрацию препарата в зоне поражения. Однако в литературе нет четких показаний к назначению антибактериальных препаратов интратекально, что и определяет актуальность разработанного способа.

Клиническое наблюдение:

Пациент, военнослужащий, (40 лет) поступил в госпиталь Минобороны России 14.12.2014 г. в 00:25 с жалобами: на отеки конечностей, боли в правом подреберье. $\mathrm{T}^{0}$ тела 37,7 0С. Из анамнеза: с 2007 года диагностируется ВИЧ-инфекция, по поводу чего обследовался в специализированном военном госпитале. Диагноз подтверждён, признан годным к военной службе. На Д-учете в СПИД центре не состоял. В дальнейшем, по поводу ВИЧ-инфекции не обследовался, не лечился. Состояние средней степени тяжести.

Объективно: в сознании, слегка заторможен. Кожные покровы землисто-желтого цвета, склеры субиктеричны. Распространенные отеки конечностей. Тоны сердца ясные, ритмичные, ЧСС 120 уд. в мин. АД 120/80 мм рт. ст. Дыхание везикулярное, хрипов нет. Язык суховат, обложен белым налетом. Живот мягкий, чувствительный в правом подреберье. Менингеальных и очаговых симптомов не выявлено. Через мочевой катетер выведено 50 мл. темно-желтой мочи. Пациент госпитализирован в терапевтическое отделение, Ds: Отечный синдром неясного генеза. Консультирован дежурным хирургом: данных за острую хирургическую патологию не выявлено. В анамнезе с 2007 года ВИЧ-инфицированный больной, стадия 2-Б, бессимптомное течение. Данные лабораторных исследований - ОАК: эритроциты $3,12 * 10^{12} /$ л; $\mathrm{Hb} 80$ г/л; лейкоциты $3,1 * 10^{9} /$ л; тромбоциты $184,0 * 10 \%$ /л; п/я. $2 \%$; с/я. $75 \%$; мон. $2 \%$. Биохимический анализ крови: общий билирубин 9,5 мкмоль/л; амилаза 15 Е/л; АСТ 49 Е/л; АЛТ 15 Е/л; креатинин 63 мкмоль/л, мочевина 4 мкмоль/л; общий белок 61 г/л; ПТИ 77; фибриноген 3,8 г/л; К 4,0 ммоль/л; NA 145 ммоль/л; СІ 105 ммоль/л; глюкоза 3,9 ммоль/л; альбумин 16 г/л. Анализ на ВИЧ положительный. HbsAg отрицательный. Анализ мочи: цвет темно-желтая; прозрачность — мутная; удельный вес 1030; реакция кислая; белок - 0,156 г/л; лейкоциты 9-10 в п/3; эритроциты свеж. 4-5 в п/3. выщ. 3-4 в п/3; слизь ++. Консультирован инфекционистом 13.12.2014 г.: выставлен Ds: BИЧ инфекция. Для уточнения стадии и фазы рекомен- 
Н. В. Шевченко, С. М. Кузнецов, А. Д. Дармаев и др. Сложный диагностический случай менингоэнцефалита у пациента с ВИЧ-инфекцией

дована консультация в ИОЦ СПИД и ИЗ. Консультирован ЛОР-врачом: патологии не выявлено. Консультирован окулистом: патологии не выявлено. Консультирован неврологом: проявление ВИЧ-энцефалопатии средней тяжести.

15.12.2014 г., в 13:00, в связи с угнетением сознания до уровня умеренного-глубокого оглушения, для динамического наблюдения пациент переведен в ОАиР.

В последующем, больной находясь в отделении АИР ежедневно был осмотрен врачами анестезиологами-реаниматологами и дежурными врачами, но, данных за поражение нервной системы не были выявлены.

18.12.2014 г., по решению консилиума, в связи с некоторым улучшением состояния больного, переведен для дальнейшего лечения в инфекционное отделение.

26.12.2014 г. у пациента отмечалось ухудшение состояния, до тяжелого. Снижение уровня сознания до глубокого оглушения; пациент переведен в ОАиР.

Заключение невролога 26.12.2014 г. - у больного проявление ВИЧэнцефалопатии средней степени тяжести, не исключается развитие подострого энцефалита (выявлены симптомы раздражения менингеальных оболочек, в виде сомнительного нижнего симптома Брудзинского).

Люмбальная пункция 26.12.2014 г. Ликвор: белок до 0,825 г/л; плеоцитоз 20/3. (лимфоциты). Рекомендовано к лечению добавить сосудистые препараты. Бактериологическое исследование ликвора, мокроты, крови, мочи патологической микрофлоры не выявило. К лечению добавлена противовирусная терапия (Виферон 2 млн МЕ в сутки).

По назначению лечащего врача назначено МРТ головного мозга 30.12.2014 г. Заключение: картина менингоэнцефалита с поражением правой ножки мозга, медиабазальных отделов правой височной доли, подкорковых структур слева.

30.12.2014 г. после консультации в ИОЦ СПИД и ИЗ выставлен Ds: в 20.7 (В 20.1 + В 20.9) ст. 4B. AIDS фаза прогрессии без BAAPT. Менингоэнцефалит неуточненной этиологии. Энцефалопатия смешанного генеза (ВИЧ-ассоциированная. ВИЧ-деменция и дисметаболическая). Дисметаболическая сенсомоторная полинейропатия. Очаговая пневмония 10 сегмента правого легкого, в стадии разрешения. Сопутствующий Ds: Цирроз печени, как исход хронического гепатита неясного генеза; класс В по Чайлд-Пью, стадия субкомпенсации. Портальная гипертензия. Нефропатия смешанного генеза. Получает этиотропную терапию.

09.01.2015 г. Уровень сознания сопор. 
12.01.2015 г. нарастает дыхательная недостаточность. Выполнена интубация трахеи, начата ИВЛ. В смывах из трахеобронхиального дерева (ТБД) высеян Cryptococcusneoformans.

19.01.2015 г. выполнена операция - трахеостомия.

25.01.2015 г. состояние пациента крайне тяжелое с отрицательной динамикой. Уровень сознания кома І. Продолжается ИВЛ. Отмечается нестабильность гемодинамики (гипотензия до 80 и 40 мм рт. ст.) Проводится инотропная поддержка дофамином в дозе 5-7 мкг/кг.мин.

27.01.2015 г. На фоне проводимого лечения состояние крайне тяжелое, обусловленное полиорганной недостаточностью, в последующих общих анализах крови лейкоцитоз сменился на прогрессирующую лейкопению и анемию $\left(\mathrm{Hb} 107 \rightarrow 82 \Gamma / л ; ~ Э р ~ 3.5 \rightarrow 2.7 \times 10^{12}\right.$; Лейк $\left.10.6 \rightarrow 1.9 \times 10^{9}\right)$. В биохимических анализах, на фоне снижения уровня трансаминаз (с $461 \mathrm{E} /$ л. до 129 Е/л.) продолжающаяся гипопротеинемия (с 48.8 г/л) гипоальбуминемия (26.4 г/л), что привело к значительному нарастанию периферических отёков. Уровень сознания кома II. Продолжается ИВЛ. Прогноз для жизни не благоприятный.

31.01.2015 г. в 22:50 на фоне прогрессивного ухудшения состояния и проводимого лечения произошла остановка сердечной деятельности.

Проводимые реанимационные мероприятия в полном объеме неэффективны.

31.01.2015 г. в 23:30 констатирована биологическая смерть.

Посмертный диагноз: В 20.7 (В 20.1+ В 20.9+ В20,5) ВИЧ-инфекция стадия 4B AIDS фаза прогрессии без AРВT. Криптококкоз. Криптококковая пневмония нижней доли правого легкого. ВИЧ - ассоциированный менингоэнцефалит, неутонченной этиологии тяжелого течения. Мультифокальное поражение головного мозга, проявляющееся правосторонним центральным гемипарезом, судорожным, бульбарным, гипертермическим синдромом. Острый гломерулонефрит, смешанная форма, осложненная острой почечной недостаточностью. Полисерозит (асцит, гидроперикард, двусторонний гидроторакс). Выраженные иммунологические CD4 0,048x109 и гематологические нарушения в виде лейко-, тромбоцитопении, анемии. Получает дезинтоксиционную, общеукрепляющую, сосудистую, антибактериальную и противогрибковую терапию.

Патологоанатомический диагноз 17.02.1015 г.: Генерализованная вирусная инфекция с поражением мозга, печени, почек, легких. Вирусный менингоэнцефалит. Лимфоцитарная инфильтрация мягкой мозговой оболочки, перивазальные лимфоцитарные муфты, очаги повреждений вещества головного мозга. Очаговые лимфоцитарные инфильтраты в почках с признаками повреждения клубочков. Утолщение мезангия, подчеркнутая дольчатость клубочков, склероз части клубочков. Очаговые инфильтраты 
Н. В. Шевченко, С. М. Кузнецов, А. Д. Дармаев и др. Сложный диагностический случай менингоэнцефалита у пациента с ВИЧ-инфекцией

в печени с локализацией в портальных трактах и внутри долек. Скудные рассеянные лимфоцитарные инфильтраты в легких. Осложнения: печеночно-почечная недостаточность. Анемия. Гипопротеинемия, гипоальбуминемия. Судорожный синдром. Нарушения дыхания. Трахеостомия. ИВЛ. Отек головного мозга. Отек легких.

Выводы:

Наличие у больного ВИЧ-инфекции всегда должно настораживать о том, что сопутствующее заболевание, может протекать с минимальными (иногда бессимптомными) клиническими признаками: (общеинфекционными, менингеальными и очаговыми симптомами). Ведущую роль в постановке диагноза, в таких случаях, играют дополнительные методы исследования (КТ, МРТ, МСКТ головного мозга и данные люмбальной пункции). Назначенная этиотропная терапия менингоэнцефалита (у больного с сопутствующей ВИЧ-инфекцией) - не всегда помогает в лечении данной патологии у больного с ВИЧ-инфекции, в виду ослабленного иммунитета. Системное поражение у ВИЧ-инфицированных без АРВТ, усугубляет и отягощает течение основного заболевания приводит к полиорганной недостаточности и, нередко, к летальному исходу.

Динамическое наблюдение ВИЧ-инфицированных пациентов позволяет своевременно выявить первичные признаки поражения органов и систем и своевременно справиться с возникающими осложнениями.

\section{Литература}

1. Бартлетт Дж., Галлант Дж., Фам П. Клинические аспекты ВИЧинфекции. 2009-2010. М., 2010. С. 40-45.

2. Богомолов Б. П. Диагностика вторичных и первичных менингитов // Эпидемиология и инфекционные болезни. 2007. № 4. С. 5-33.

3. Актуальные проблемы диагностики и лечения бактериальных менингитов / Ю. Я. Венгеров [и др.] // Лечащий врач. 2007. № 9. С. 5-31.

4. Васильева Н. В. Факторы патогенности Cryptococcusneoformans и их роль в патогенезе криптококкоза: дис. ... д-ра биол. наук. СПБ., 2005. C. 21-26.

5. Клиника и диагностика криптококкового менингоэнцефалита у больных ВИЧ-инфекцией / Ю. Я. Венгеров [и др.] // Материалы V ежегодного Всероссийского конгресса по инфекционным болезням. М., 2013. C. 85.

6. Елинов Н. П., Босак И. А. Прошлое и настоящее Cryptococcusneoformans (Sanfelice) Vuilemin (1901) как объекта изучения потенциально грозного патогена для человека // Проблемы медицинской микологии. 2006. № 8(2). С. 47-51. 
7. Особенности течения туберкулезного менингоэнцефалита у больных с поздними стадиями ВИЧ-инфекции / Э. Х. Корнилова [и др.] // Журн. неврол. и психиатр. 2013. № 12. С. 13-18.

8. Климко Н. Н. Микозы центральной нервной системы. СПб., 2011. C. $18-24$.

9. Лесовой В. С., Липницкий А. В. Микозы центральной нервной системы (обзор) // Проблемы медицинской микологии. 2008. № 10(1). С. 3-6.

10. Сергеев А. Ю., Сергеев Ю. В. Грибковые инфекции: руководство для врачей. М.: Бином-пресс, 2003. С. 78-85.

11. Хмельницкий О. К., Хмельницкая Н. М. Патоморфология микозов человека. СПб.: СПбМАПО, 2005. С. 28-36.

12. Шмерига Г. С., Синицын М. В. Туберкулезный менингоэнцефалит у больных ВИЧ-инфекцией: диагностика и особенности течения // Туберкулез и социально значимые заболевания. 2016. № 3. С. 67-68.

13. Baddley J. W., Perfect J. R., Oster R. A. Pulmonary cryptococcosis in patients without HIV infection: factors associated with disseminated disease // Eur. J. Clin. Microbiol. Infect. Dis. 2008. № 27(10). P. 43-937.

14. Bartlett D., Galant D. Clinical aspects if HIV infection. Baltimor: Dzhonsa Hopkinsa, 2006. P. 112-125.

15. Bartlett D., Gallant J., Pham P. Clinical Aspects of HIV. Moscow, 2010. P. 74-85.

16. Del Poeta M. Role of phagocytosis in the virulence of Cryptococcosis neoformans // Eukaryot. Cell. 2004. № 3(5). P. 75-1067.

17. Kielholner M., Atmar RL, Hamill RJ, et al. Life-threatening Pseudomonas aeruginosa infections in patients with human immunodeficiency virus infection // Clin Infect Dis. 1992. № 14. P. 11-403.

18. Miziara I. Otitis media in Brazilian human immunodeficiency virus infected children undergoing antiretroviral therapy // J.Laryngol. Otol. 2007. Vol. 121, № 11. Pp. 1048-1054.

19. Patel N., Goodman J., Singh A. Bezold's abscess in the setting of untreated HIV infection // Laryngoscope. 2010. Vol. 120, № 4. P. 134.

20. Li S. S., Mody C. H. Cryptococcus. Proc. Am. // Thorac. Soc. 2010. № 7(3). Pp. 96-186.

21. Larsen R. A., Bauer R., Thomas A. M. et al. Amphotericin B and fluconazole. A potent combination therapy for cryptococcal meningitis // Agents Chemother. 2004. № 48(3). Pp. 7-985. 
Н. В. Шевченко, С. М. Кузнецов, А. Д. Дармаев и др. Сложный диагностический случай менингоэнцефалита у пациента с ВИЧ-инфекцией

COMPLEX DIAGNOSTIC CASE OF MENINGOENCEPHALITIS

IN PATIENT WITH HIV INFECTION

Shevchenko N. Vasilevich

Lieutenant Colonel of medical service

s.m.kusnetzov@yandex.ru

Kuznecov S. Mironovich

doctor of higher category

Head of operational Department

Associate Professor,

s.m.kusnetzov@yandex.ru

Darmaev A. Dashievich

higher category neurologist

darmaevag@mail.ru

Ochirov B. Vladimirovich

lieutenant Colonel of medical service,

doctor infectious disease specialist

head of infectious

darmaevad@mail.ru

Scheikova I. Aleksandrovna

doctor infectious disease specialist

infecctious diseases unit resident

905irina@mail.ru

Zyryanov A. Anatolevich

resident of the Depsrtament of Anasthesiology

darmaevad@mail.ru

Branch 1 Fgku "425-Vg" Mo RF

1, Hospital Str., Irkutsk, 664009, Russia

Pyrenkov D. Aleksandrovich

lieutenant Colonel of medical service

doctor Anesthesiologist Head of Anesthesiology Department

Arkhangelsk hospital

5, Roses Luxembourg Str., Astrakhan, 414000, Russia

s.m.kusnetzov@yandex.ru 
Miscavige A. Sergeevich

the captain of the medical service

Head of Department of Anesthesiology and resuscitation

mits.oar38mail.ru

Washenko P. Pavlovth

the captain of the medical service

resident of Department of Anesthesiology and resuscitation

mits.oar38mail.ru

Shinkorenko V. Stanistavovna

Head of neurological Department

branch 1 FGKU "425 VG" MO RF

vikstan24@mail.ru

Branch 1 Fgku "425-Vg" Mo Rf

1, Hospital Str., Irkutsk, 664009, Russia

Makarova N. Alexandrovna

neurologist, primary offices

specialized health services

help OGBUZ "N 3 IGKB»»

31, Timerjazeva Str., Irkutsk, 664003, Russia

mak.na@list.en

Targashina T. Borisovna

Lieutenant Colonel of medical service

Head of the therapeutic Department

targashina.t@mail.ru

Sidelnikov A. Penrovth

Neurologic scintillation departament

1007Petz@mail.ru

Onishchuk Ju. Vladimirovna

the Chief of staff

onishchuk.y@inhox.ru

Branch 1 Fgku "425-Vg" Mo RF

1, Hospital Str., Irkutsk, 664009, Russia 
Н. В. Шевченко, С. М. Кузнецов, А. Д. Дармаев и др. Сложный диагностический случай менингоэнцефалита у пациента с ВИЧ-инфекцией

Abstract. The arcticleprovidens clinical is observation of the patient is difficult to diagnose on the meningoencephalitis background of HIV infection. On admission to the hospital in a patient not been indentifiedno typicalsymptom for meningoencephalitis? The presence of marked edema was notedon the legs hospitalization os a therapeutic department. Patient condicion worsened, transferred to intensive care. Only dynamic obserwation, consultation of athers specialists of all profiles, 6 the use of moderncomputer technologies made it possible to diagnose meningoencefalitis.

Keywords: meningoencephalitis, HIV infection 